\title{
ARTICLE
}

\section{Urotensin II and urantide exert opposite effects on the cellular components of atherosclerotic plaque in hypercholesterolemic rabbits}

\author{
Qing-qing Yu ${ }^{1}$, Da-xin Cheng ${ }^{1}$, Li-ran $\mathrm{Xu}^{1}$, Yan-kui $\mathrm{Li}^{2}$, Xiao-ya Zheng ${ }^{2}$, Yi Liu ${ }^{1}$, Ya-feng Li ${ }^{1}$, Hao-le Liu ${ }^{1}$, Liang Bai ${ }^{1}$, Rong Wang ${ }^{1}$, \\ Jiang-lin Fan ${ }^{3}$, En-qi Liu ${ }^{1,4}$ and Si-hai Zhao ${ }^{1,2,4}$
}

Increasing levels of plasma urotensin II (UII) are positively associated with atherosclerosis. In this study we investigated the role of macrophage-secreted UII in atherosclerosis progression, and evaluated the therapeutic value of urantide, a potent competitive UII receptor antagonist, in atherosclerosis treatment. Macrophage-specific human UII-transgenic rabbits and their nontransgenic littermates were fed a high cholesterol diet for 16 weeks to induce atherosclerosis. Immunohistochemical staining of the cellular components (macrophages and smooth muscle cells) of aortic atherosclerotic lesions revealed a significant increase (52\%) in the macrophage-positive area in only male transgenic rabbits compared with that in the nontransgenic littermates. However, both male and female transgenic rabbits showed a significant decrease ( $45 \%$ in males and $31 \%$ in females) in the smooth muscle cellpositive area compared with that of their control littermates. The effects of macrophage-secreted UII on the plaque cellular components were independent of plasma lipid level. Meanwhile the wild-type rabbits were continuously subcutaneously infused with urantide $\left(5.4 \mu \mathrm{g} \cdot \mathrm{kg}^{-1} \cdot \mathrm{h}^{-1}\right)$ using osmotic mini-pumps. Infusion of urantide exerted effects opposite to those caused by UII, as it significantly decreased the macrophage-positive area in male wild-type rabbits compared with that of control rabbits. In cultured human umbilical vein endothelial cells, treatment with UII dose-dependently increased the expression of the adhesion molecules VCAM-1 and ICAM-1, and this effect was partially reversed by urantide. The current study provides direct evidence that macrophage-secreted UII plays a key role in atherogenesis. Targeting UII with urantide may promote plaque stability by decreasing macrophage-derived foam cell formation, which is an indicator of unstable plaque.

Keywords: urotensin II; urantide; atherosclerosis; plaque; macrophage

Acta Pharmacologica Sinica (2020) 41:546-553; https://doi.org/10.1038/s41401-019-0315-8

\section{INTRODUCTION}

Cardiovascular disease (CVD) arising from atherosclerosis remains the leading cause of death in both developed and developing countries except for Africa [1-3]. Coronary artery disease and stroke account for $80 \%$ of CVD deaths in males and $75 \%$ of CVD deaths in females [3]. Many vasoactive peptides, inflammatory cytokines, and oxidative products are involved in the progression of atherosclerosis [4]. Atherosclerotic plaque is shaped by the interplay of pro- and antiatherogenic factors both within the atherosclerotic aorta and systemically [4-6]. Urotensin II (UII) is a vasoactive cyclic peptide that is composed of 11 amino acids that are highly expressed in the human cardiovascular system together with its $G$ protein-coupled receptor GPR14, now known as the urotensin II receptor (UTR) $[7,8]$. Clinical studies have shown positive correlations between increased plasma UII level and the severity of atherosclerosis in coronary and carotid arteries, diabetes mellitus and renal failure [9-14]. Studies in animal models also show that UII may participate in the development of atherosclerosis [15-17].

It is generally established that unstable plaque is the major cause of acute clinical sequelae of atherosclerosis [18]. The cellular components, necrotic core size, collagen fiber content, and other systemic risk factors all contribute to plaque destabilization [18-22]. Circulating UII was reported to promote atherosclerosis progression and foam cell formation in animal models $[15,16]$. Circulating UII increases plasma reactive oxygen species levels, oxidizes low-density lipoprotein and upregulates the expression of matrix metalloproteinases 1 and 9, scavenger receptors and acyl-CoA, which are important molecules in the initiation and progression of atherosclerosis [15, 16, 23]. In addition to systemic effects, many active biological peptides can also exert a wide range of biological effects, especially in regards to the regulation of cardiovascular homeostasis, local and generalized inflammation, and cell proliferation and migration in autocrine, paracrine, and endocrine manners [24-26]. Whether

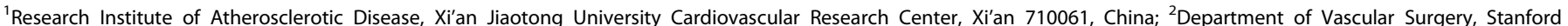

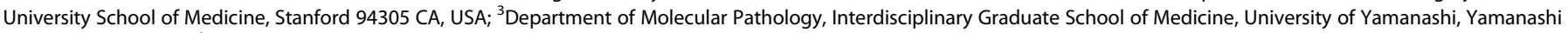
409-3898, Japan and ${ }^{4}$ Laboratory Animal Center, Health Science Center of Xi'an Jiaotong University, Xi'an 710061, China

Correspondence: Si-hai Zhao (sihaizhao@xjtu.edu.cn) or En-qi Liu (liuenqi@xjtu.edu.cn)

These authors contributed equally: Qing-qing Yu, Da-xin Cheng

Received: 3 May 2019 Accepted: 30 September 2019

Published online: 4 November 2019 
autocrine/paracrine UII changes the cellular components of plaque and contributes to its destabilization remains to be studied, and whether an in vivo blockade of UII provides protection against atherosclerosis or improves plaque stability should be clarified.

Rabbit models are widely used in atherosclerosis research because of several advantageous traits. The lipoprotein metabolism of rabbits closely mimics that of humans, and their larger size facilitates noninvasive arterial analysis and provides sufficient arterial tissues and atherosclerotic lesions for harvest [27, 28]. Rabbits are susceptible to cholesterol-induced atherosclerosis, with lesions resembling those observed in human atherosclerosis, ranging from early-stage lesions (fatty streaks) to complicated lesions (fibrous plaques). In this study, previously created macrophage-specific Ull-overexpressing transgenic rabbits were used to study the role of autocrine/paracrine UII in the cellular components of plaque [17]. This newly created model with locally overexpressed UII is an idea tool to clarify the role of autocrine/ paracrine UII in atherosclerosis development. Urantide, an ultrapotent UII antagonist peptide [29], was also continuously infused into hyperlipidemic rabbits by osmotic mini-pumps to study its effects on plaque progression compared with those of UII and to evaluate the potential therapeutic value of UII/UTR as an atherosclerotic plaque target.

\section{MATERIALS AND METHODS}

Animals

The generation of transgenic rabbits expressing human UII (hUII) in macrophages was conducted in our laboratory by microinjection as described previously [17]. hUll transgenic rabbits $(n=7$ male and $n=10$ female) and their nontransgenic littermates ( $n=$ 7 male and $n=10$ female) were fed a high cholesterol diet (HCD, $0.3 \%$ cholesterol) for 16 weeks to induce atherosclerosis. Male wild-type Japanese white rabbits were supplied by the Laboratory Animal Center of Xi'an Jiaotong University for urantide infusion. To avoid the hemodynamic effects induced by an intravenous bolus injection, urantide $\left(5.4 \mu \mathrm{g} \cdot \mathrm{kg}^{-1} \cdot \mathrm{h}^{-1}, \mathrm{GL}\right.$ Biochem, Shanghai, China) was continuously subcutaneously infused with osmotic mini-pumps (Alzet Model 2006, Durect, Cupertino, CA, USA). The osmotic mini-pumps were loaded with either urantide dissolved in saline (vehicle) or vehicle and implanted subcutaneously at the backs of the necks of rabbits anesthetized with isoflurane. The osmotic pumps were replaced every 6 weeks. All rabbits were fed an HCD for 16 weeks. The experimental protocols were approved by the Laboratory Animal Administration Committee of Xi'an Jiaotong University and were performed according to the Guidelines for Biomedical Experimentation of Xi'an Jiaotong University (No. 2017-582).

Measurement of body weight, plasma lipids, and blood pressure The body weights and plasma lipid levels of all rabbits were measured every 2 weeks. After $16 \mathrm{~h}$ of food deprivation, blood samples were collected via the auricular artery using an EDTA anticoagulant tube and then centrifuged $\left(3000 \mathrm{rpm}, 15 \mathrm{~min}, 4^{\circ} \mathrm{C}\right.$ ) to obtain plasma. The plasma levels of total cholesterol, triglycerides (TG), and high-density lipoprotein-cholesterol (HDLC) were measured using BioSino assay kits (Bio-Technology \& Science, Inc., Beijing, China). The plasma levels of tumor necrosis factor- $a$ (TNF- $\alpha$ ) and interleukin- 6 (IL-6) were measured with ELISA kits according to the manufacturer's instructions (R\&D Systems, Minneapolis, MN, USA). At the end of the experiment, blood pressure (BP) was measured in each group of rabbits as previously described [30]. Briefly, the rabbit medial auricular artery was cannulated with a $23 \mathrm{G}$ cannula, and the BP and heart rate were recorded using a transducer positioned at heart level in a quiet room. After the rabbits became calm, data were collected for
12-25 min using PowerLab (ADInstruments, Bella Vista, New South Wales, Australia).

Atherosclerotic lesion analysis

At the end of the experiment, the rabbits were euthanized by an overdose of sodium pentobarbital to enable analysis of the atherosclerotic lesions. The entire aortic tree was fixed in $10 \%$ neutral buffered formalin and stained with Sudan IV (Yongsheng Chemical Co., Ji-nan, China). The area of the atherosclerotic lesion (sudanophilic area) was measured using image analysis software (WinRoof 6.5, Mitani Co. Ltd., Tokyo, Japan). For microscopic quantification of the lesion area, each segment of the rabbit aorta was cut into cross sections (8-10 for the aortic arch and 20 for the thoracic aorta) as described previously [15]. For microscopic evaluation of the cellular components in the lesions, serial paraffin sections of the thoracic aortas were immunohistochemically stained with antibodies (Abs) against macrophages $(M \varphi)$ (1:500; RAM11, Dako, Glostrup, Denmark) and smooth muscle cells (SMCs) (1:400; a-actin, Thermo, Carlsbad, USA). To further explore the plaque components, we also performed Masson's trichrome and immunohistochemical staining with Abs against MMP-2 (1:800; MAB3308, Millipore, Darmstadt, Germany) and MMP-9 (1:50; IM37, Millipore, Darmstadt, Germany). The sections for microscopic quantification were examined and photographed under a microscope equipped with a digital camera and measured with the previously mentioned image analysis software. The cellular component analysis of circled plaque was performed by excluding the artery wall with image software.

Adipose tissue and organ sample collection

At the end of the 16-week experiment, rabbits were euthanized, and adipose tissues throughout the body were carefully removed and weighed. We divided adipose tissues into (i) subcutaneous adipose tissue, including fat from the inguinal, axilla, and scapular regions, and (ii) visceral adipose tissue from the abdominal cavity, mesenterium, and retroperitoneal fat. The liver, skeletal muscle (soleus), kidney, spleen, heart, lung, pancreas, and bone marrow were removed, weighed and fixed in $10 \%$ neutral buffered formalin for subsequent morphological analysis.

In vitro human umbilical vein endothelial cell experiments Human umbilical vein endothelial cells (HUVECs) were isolated from human umbilical cords using $0.1 \%(w / v)$ collagenase and then cultured in M199 medium supplemented with $20 \%$ fetal bovine serum (Gibco/Invitrogen, Carlsbad, CA, USA), $100 \mathrm{U} / \mathrm{mL}$ penicillin (Life Technologies, Carlsbad, CA, USA), $100 \mathrm{mg} / \mathrm{mL}$ streptomycin (Life Technologies), $100 \mathrm{mg} / \mathrm{mL}$ heparin sodium (Fluka/Sigma-Aldrich, St. Louis, MO, USA), and $1 \%(v / v)$ endothelial cell growth supplement (ScienCell Research Laboratories, Carlsbad, CA, USA). Cultured HUVECs were treated with UII (50 nM, GL Biochem, China) alone or UII together with the UII receptor antagonist urantide $(50 \mathrm{nM})$ for $24 \mathrm{~h}$. Cellular protein aliquots (20 mg) were separated by $10 \%$ SDS-PAGE and subjected to Western blotting with rabbit polyclonal Abs against human vascular cell adhesion molecule-1 (VCAM-1) (Epitomics, Burlingame, CA, USA) and intercellular adhesion molecule-1 (ICAM-1) (Epitomics, Burlingame, CA, USA). Umbilical cords were obtained from participants who provided informed consent. The protocol was approved by the Xi'an Jiaotong University Ethics Committee. The investigation also adhered to the principles outlined in the Declaration of Helsinki for the use of human tissues or subjects.

Statistical analysis

Data are expressed as the mean \pm SEM. Statistical analysis was performed using Student's $t$ test with an equal $F$ value or Welch's $t$-test when the $F$ value was not equal. For more than two groups, 
a
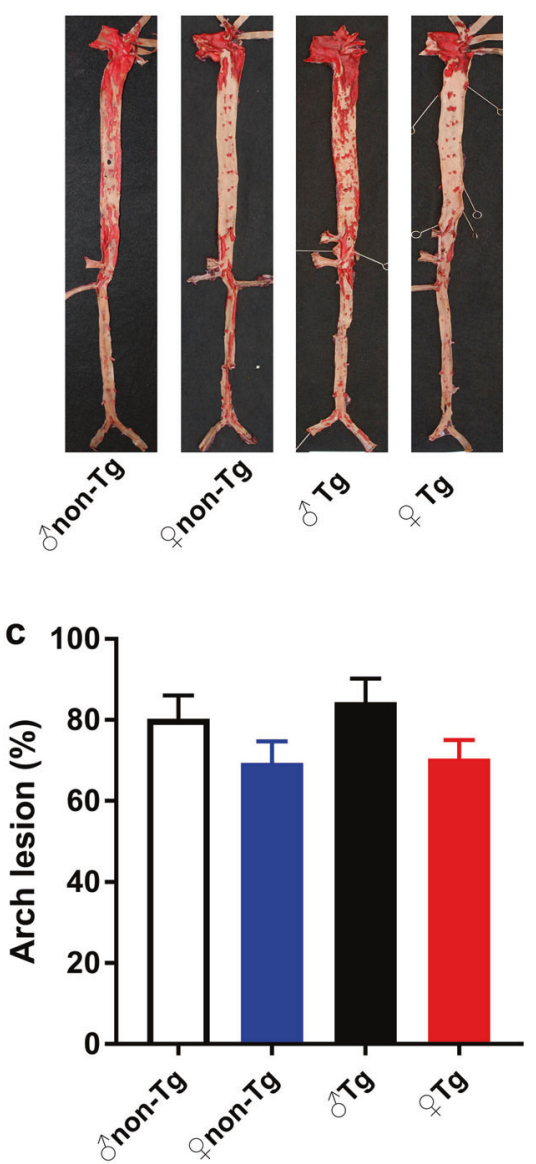

b
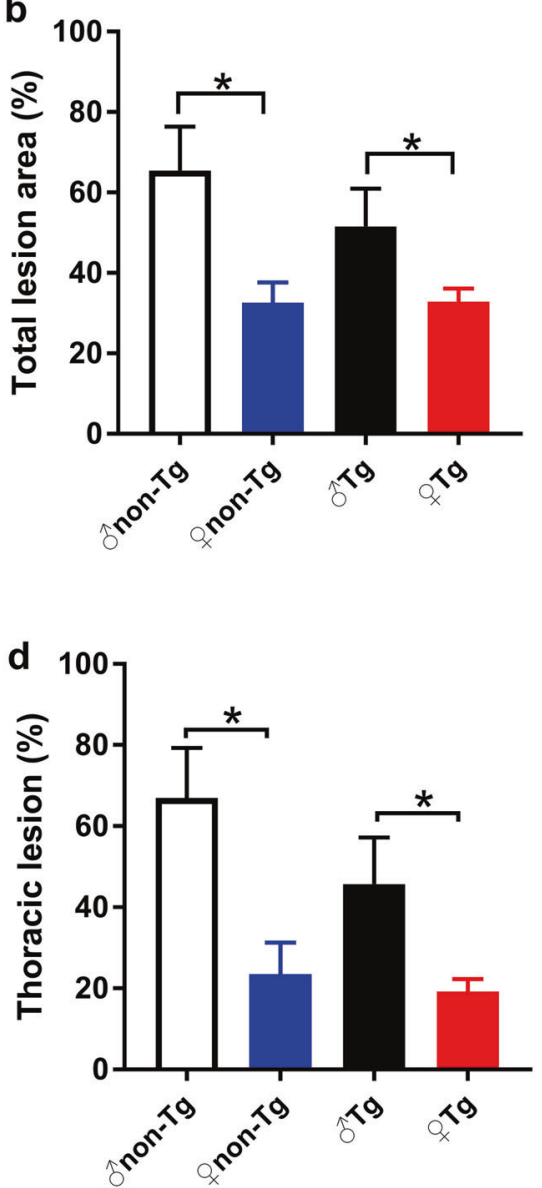

Fig. 1 Quantitation of aortic atherosclerosis by en face Sudan IV staining in UII-transgenic rabbits and their nontransgenic littermates. $\delta^{\star}$ male, o female, Tg transgenic, Non-Tg nontransgenic. Data are expressed as the mean \pm SEM. $n=7-10$ for each group. ${ }^{*} P<0.05$

one-way ANOVA was conducted. $P<0.05$ was considered significant.

\section{RESULTS}

The plasma parameters and gross plaque size in transgenic rabbits The generation of transgenic rabbits expressing hUll in macrophages was conducted in our laboratory by microinjection as described in a previous study [17]. In the transgenic rabbit experiment, both male and female rabbits were used to observe the role of macrophages-overexpressing hUll in the progression of atherosclerosis and the existence of sex differences. As shown in Supplementary Fig. 1, with HCD-induced hyperlipidemia, the plasma lipid levels in female rabbits were higher than those in male rabbits in both transgenic and nontransgenic animals. In transgenic rabbits, the lipid levels of females were significantly higher than those of males (Supplementary Fig. 1e, f).

However, analysis of the en face aortic lesion areas revealed that the whole aortic atherosclerotic lesions of males were significantly larger, by $100 \%$ in nontransgenic rabbits and $56 \%$ in transgenic rabbits, than those of females (Fig. 1). The thoracic lesion size mainly contributed to this difference (Fig. 1d). When same-sex transgenic and nontransgenic rabbits were compared, no significant difference was found. These results showed that the sex differences in plaque were not significantly affected by macrophages-overexpressing UII. However, autocrine/paracrine UII in macrophages also did not significantly change the gross lesion size in transgenic rabbits compared with that in their nontransgenic littermates.
Overexpressed UIl changes the cellular components of arch plaque

We further examined sections of plaque under a light microscope and quantified the lesion areas. Photographs of the aortic arch cross-section stained with hematoxylin-eosin and elastica van Gieson are shown in Fig. 2a. Histological examinations revealed that the lesions in all rabbits mainly consisted of fatty streaks. Macrophages-overexpressing UII did not markedly change the microscopic lesion size in any animals (Fig. 2a, b). We next quantified the cellular components (macrophage- and SMCpositive), revealing a significant increase of $52 \%$ in the macrophage-positive area in male transgenic rabbits compared with that in their nontransgenic littermates (Fig. 2c). However, both male and female transgenic rabbits showed significant decreases, $\sim 1$-fold, in the proportion of the SMC-positive area compared with that in nontransgenic rabbits (Fig. $2 \mathrm{~d}$ ). To evaluate the collagen content, we stained the sections with Masson's trichrome. Compared with that in nontransgenic rabbits, the collagen content in transgenic rabbits was decreased (Supplementary Fig. 2). There was no obvious difference in body weight, with similar food consumption, in all rabbits at either the start or the end of the experiment (Supplementary Fig. 3a, b). The adipose tissue weight was not significantly altered by macrophagesoverexpressing UII in comparison with that in control nontransgenic rabbits (Supplementary Fig. 3d-f). The adipose tissue weight in females tended to be higher than that in males in both transgenic and nontransgenic rabbits (Supplementary Fig. 3d-f). Macrophages-overexpressing UII also slightly increased BP, but the difference was not significant (Supplementary Fig. 4). Our 

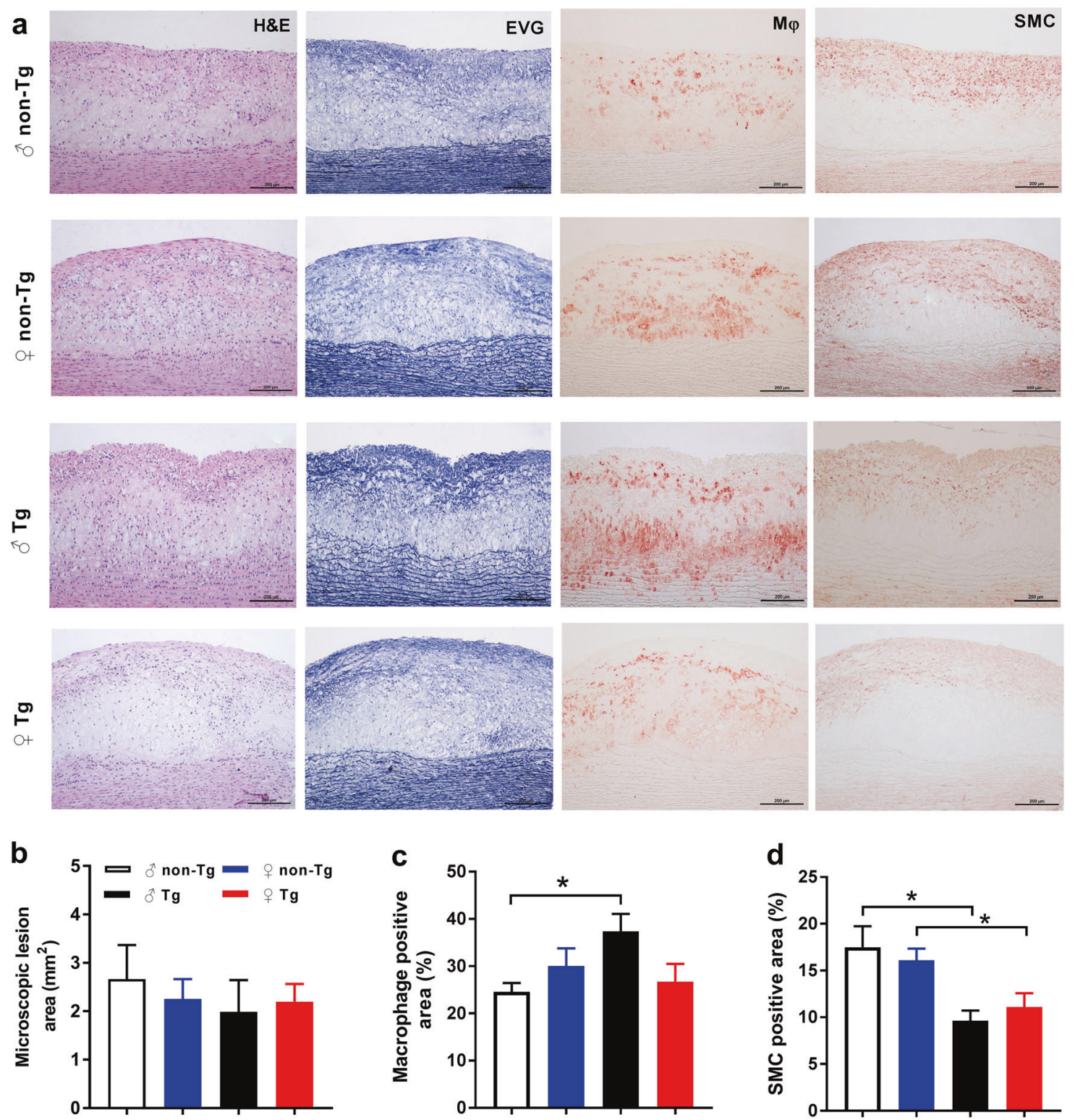

Fig. 2 Quantitation of microscopic aortic atherosclerosis. a Serial paraffin sections of the aortic arch were stained with hematoxylin-eosin (HE) and elastica van Gieson (EVG) or immunohistochemically stained with monoclonal antibodies (mAbs) against either macrophages (M $\varphi$ ) or smooth muscle $\alpha$-actin (SMA) for smooth muscle cells (SMCs). Quantitation of intimal lesions on EVG-stained sections (b) and positively stained areas of $M \varphi(\mathbf{c})$ and SMC (d). ${ }^{\widehat{*}}$ male, $\rho$ female, Tg transgenic, Non-Tg nontransgenic. Data are expressed as the mean \pm SEM. $n=7-10$ for each group. ${ }^{*} P<0.05$

previous study showed that a high level of circulating UII promotes the development of atherosclerotic lesions and destabilizes atherosclerotic plaques in male rabbits [15]. Together, our results demonstrate that both circulating and autocrine/ paracrine UII were involved in the development of plaque and that the effects of UII were more obvious in male rabbits than in female rabbits.

Effect of urantide on gross plaque size in wild-type rabbits To test whether targeting UII/UTR affects the progression of atherosclerosis, wild-type hyperlipidemic rabbits were used, as they more closely resemble the human situation than genetically modified animals. Urantide infusion did not significantly decrease the gross en face atherosclerotic lesion size in HCD-fed rabbits (Fig. 3). Compared with those in the controls, the plasma lipid levels in rabbits infused with urantide were not significantly different (Supplementary Fig. 5). The dose of urantide used also did not significantly change the BP (Table 1). Urantide only slightly affected the plasma alanine aminotransferase (ALT) and aspartate transaminase (AST) levels. The plasma levels of inflammatory cytokines, including CRP, TNF-a, and IL-6, were also measured, but the difference between groups was not significant (Table 1).

Urantide infusion inhibits macrophage-derived foam cell formation

Along with the sudanophilic en face area of the aortic arch and thoracic and abdominal aortas, microscopic measurement of the intimal lesion size and immunohistochemical quantification of the plaque cellular components (macrophages and SMCs) were performed after urantide infusion. Quantitative analysis of the cellular components showed that urantide significantly decreased the macrophage-positive area in male wild-type rabbits compared with that in controls (Fig. $4 a-c$ ). However, urantide infusion did not significantly affect the microscopic lesion size (Fig. 4b). The 

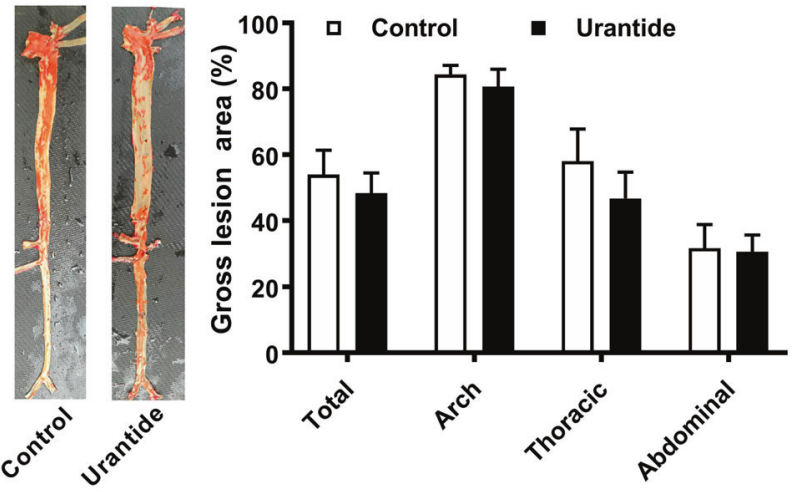

Fig. 3 Quantitation of plaque size in urantide infused and control rabbits. Data are expressed as the mean \pm SEM. $n=10$ for each group

Table. 1. Plasma cytokine, ALT, AST, and blood pressure levels in each group of rabbits

\begin{tabular}{lcc}
\hline & Control rabbits & Urantide infused rabbits \\
\hline IL-6 $(\mathrm{pg} / \mathrm{mL})$ & $186 \pm 51$ & $121 \pm 41$ \\
TNF- $\alpha(\mathrm{pg} / \mathrm{mL})$ & $225 \pm 78$ & $246 \pm 102$ \\
CRP $(\mathrm{ng} / \mathrm{mL})$ & $54 \pm 11$ & $53 \pm 8$ \\
ALT $(\mathrm{U} / \mathrm{L})$ & $38.00 \pm 2.72$ & $33.82 \pm 1.90$ \\
AST $(\mathrm{U} / \mathrm{L})$ & $19.70 \pm 1.39$ & $18.09 \pm 1.39$ \\
SBP $(\mathrm{mmHg})$ & $98.92 \pm 3.62$ & $99.56 \pm 1.87$ \\
DBP $(\mathrm{mmHg})$ & $91.44 \pm 3.74$ & $88.54 \pm 2.14$
\end{tabular}

IL-6 interleukin-6, TNF- $\alpha$ tumor necrosis factor- $\alpha, C R P$ C-reactive protein, $A L T$ alanine aminotransferase, AST aspartate transaminase, SBP systolic blood pressure, $D B P$ diastolic blood pressures

urantide infusion also increased the plaque collagen content and decreased the SMC-positive area compared with those in the control group (Fig. 4d, e). Taken together, these results indicate that tissue autocrine/paracrine UII plays an important role in shaping atherogenesis by changing cellular components, and these changes can be reversed by systemic administration of urantide.

Effects of UII and urantide on HUVEC-secreted adhesion molecules To determine the role of UII and urantide in the expression of vascular adhesion molecules in endothelial cells, cultured HUVECs were treated with different doses of UII alone or together with urantide. The VCAM-1 and ICAM- 1 mRNA levels were increased by UII in a dose-dependent manner (Fig. 5a, b). UII treatment also significantly increased the protein expression levels of VCAM-1 and ICAM-1 compared with those in the controls. The increased expression of VCAM-1 and ICAM-1 was partially reversed by urantide (Fig. 5c-e).

\section{DISCUSSION}

Accumulated clinical and laboratory evidence shows that high circulating UII levels are positively associated with the progression of atherosclerosis $[9-13,15,16]$. Atherogenesis is shaped by the interplay of pro- and antiatherogenic factors both within the atherosclerotic aorta and systemically $[5,6,31]$. Whether plaque is also affected by local cells secreting UII, such as macrophages, and whether an in vivo blockade of UII protects against atherosclerosis or improves plaque stability should be examined further. In this study, we created macrophage-specific hUll-overexpressing transgenic rabbits to explore the role of autocrine/paracrine UII in the cellular composition of lesions and its contribution to plaque destabilization. Macrophage-overexpressing UII was found to significantly increase macrophage-derived foam cell formation and decrease SMC-derived foam cell formation in male transgenic rabbits. Although the aortic plaque areas in male UII transgenic animals seemed to be slightly increased compared with those in nontransgenic animals, these effects were overshadowed by the decrease in thoracic and abdominal aortic areas. This result is potentially related to individual variance or the progression of atherosclerosis in rabbits, in which aortic plaque formation occurs earlier than that at other positions. However, local UII significantly changed only the SMC-positive area in female rabbits. The sex differences may be due to the antiatherogenic effects of estrogen in young female animals [32-34]. Sex differences are an old topic in the study of atherosclerosis. Both our laboratory and others have found that endogenous estrogen exerts antiatherogenic effects [32, 35-38]. In agreement with other studies [35-38], we also found an antiatherosclerotic effect of estrogen in female rabbits, independent of a significant influence on plasma cholesterol concentrations. Normal female rabbits [37] with a 12week $0.5 \%$ cholesterol diet and female heterozygous Watanabe heritable hyperlipidemic (spontaneous LDL receptor deficiency) rabbits [39] with a 3-year normal diet even showed higher lipid plasma values than male rabbits. These data suggest that complex hormone interactions, which are independent of changes in plasma lipids, may play an important role in the process of atherogenesis [35]. We also measured the plasma UII levels of aged inpatients with coronary artery disease, and a higher tendency was found in females than in males (Fig. 5f), demonstrating that higher UII levels may contribute to atherosclerosis in postmenopausal women. In future studies, blood samples from the atherosclerotic coronary lumen may be needed to determine the local vascular microenvironment UII levels and find an association with the plaque level. Current studies show that circulating UII is positively associated with plaque growth and vulnerability, via both systemic and local effects, such as increased $B P$, inflammatory cytokine production, and foam cell formation $[8,15,32,40-42]$. However, macrophage-specific UII overexpression was found to change the local plaque cellular components more specifically than circulating UII without systemically affecting the plasma lipid levels or BP.

In this study, UII was found to change the plaque cellular components by increasing the proportion of macrophage-derived foam cells and reducing the number of SMCs. Several reports have shown that UII promotes macrophage-derived foam cell formation and accumulation, which indicates plaque vulnerability. This study showed that in vivo local macrophages-overexpressing UII may correlate with SMC reduction and affect plaque stability. In fact, this result somewhat contradicts the increasing circulating UII, which did not exert a significant effect on SMCs in our previous study [15]. There are also some contradictory reports on the relationship between UII and SMCs in rodents. UII was reported to promote vascular SMC proliferation through store-operated calcium entry and EGFR transactivation in rat cells cultured in vitro [43]. However, UTR-knockout mice on an apoE knockout background fed a high-fat diet exhibited an enhanced hyperlipidemic and atherosclerotic phenotype, and the conclusions of that study contradicted ours [44]. In this rabbit study, local UII was found to inhibit the migration of SMCs, consistent with UTRknockout mouse reports. Along with the inhibition of SMC migration, the reduction may be correlated with foam cell formation and SMC marker loss.

As the most potent UII receptor antagonist, urantide may have potential clinical value in the treatment of atherosclerosis [45]. To consider its translational value, wild-type rabbits, which are genetically more similar to humans than gene-modified models, were continuously infused with urantide by osmotic mini-pumps 

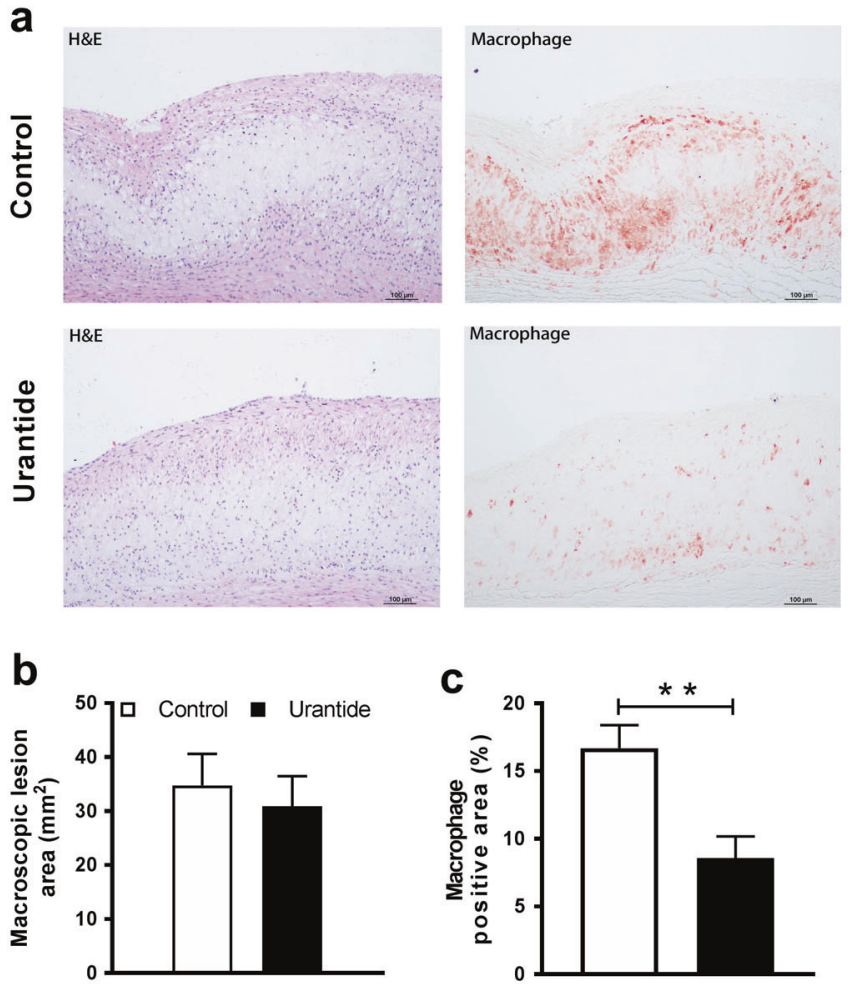

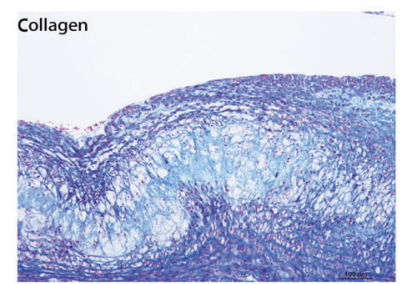

Collagen
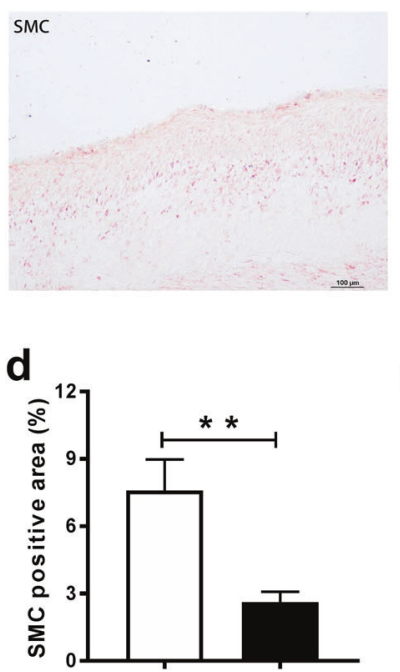
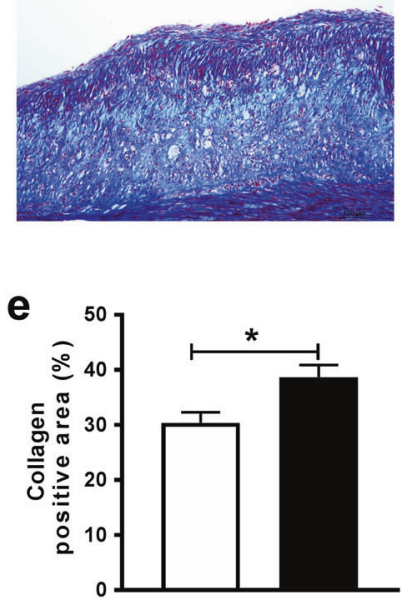

Fig. 4 Quantitation of microscopic aortic atherosclerosis. a Serial paraffin sections of the aortic arch were stained with hematoxylin-eosin (HE) and Masson's trichrome or immunohistochemically stained with monoclonal antibodies (mAbs) against either macrophages (M $\varphi$ ) or smooth muscle $\alpha$-actin (SMA) for smooth muscle cells (SMCs). Quantitation of intimal lesions on EVG-stained sections (b), positively stained areas of $\mathrm{M} \varphi(\mathbf{c})$ and SMC (d), and collagen content (e). Data are expressed as the mean \pm SEM. $n=7-10$ for each group. ${ }^{*} P<0.05$ and ${ }^{* *} P<0.01$ versus the control
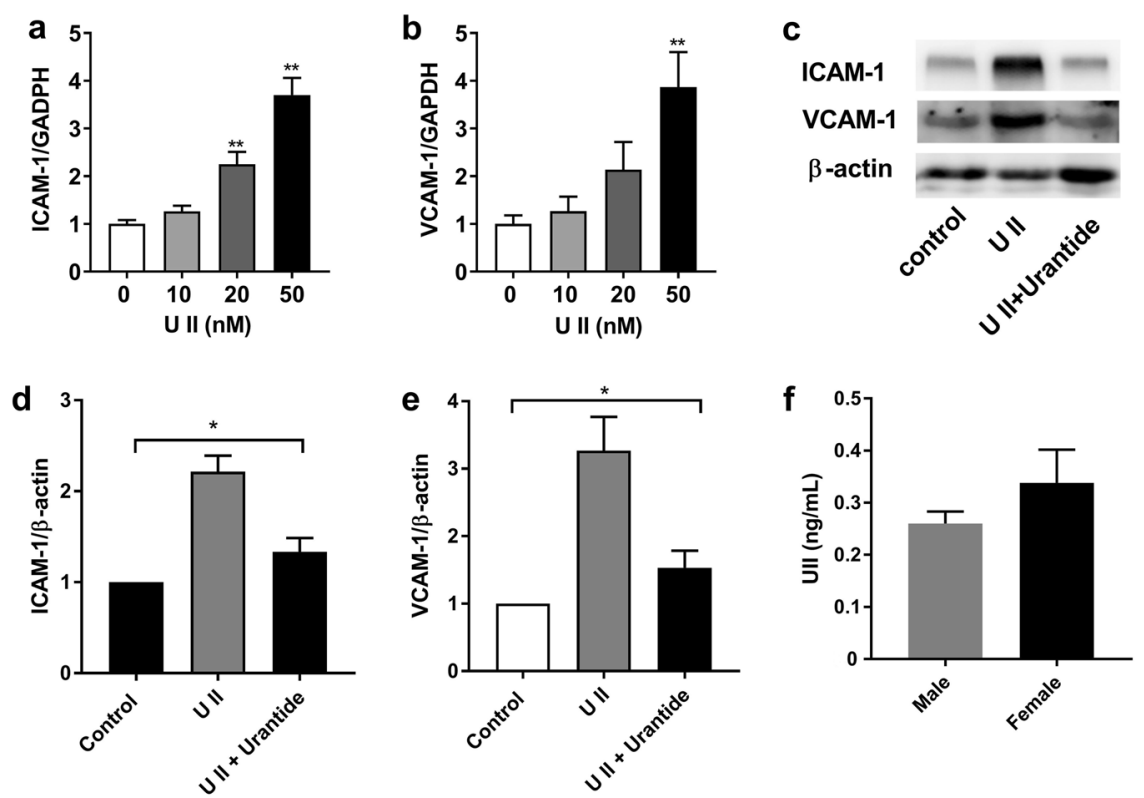

Fig. 5 Effects of UII and urantide on VCAM-1 and ICAM-1 expression in HUVECs (a-e). Dose dependent mRNA levels of VCAM-1 and ICAM-1 $(\mathbf{a}, \mathbf{b})$; protein expression levels of VCAM- 1 and ICAM-1 after treatment with $50 \mathrm{nM}$ UII with or without urantide ( $n=3$ for each group) (c, d, e); and plasma UII levels in CAD patients ( $n=24$ for males and $n=16$ for females) (f). Data are expressed as the mean \pm SEM. ${ }^{*} P<$ 0.05 and ${ }^{* * P}<0.01$

to observe its role in stabilizing atherosclerotic plaque. Urantide did not significantly decrease the gross lesions of atherosclerosis but did reduce the proportion of the macrophage-positive lesion area. Urantide also improved the plaque characteristics in hyperlipidemic rabbits by increasing the collagen content. Although urantide showed the potential to downregulate IL-6 levels, it did not significantly change the levels of other plasma cytokines, lipids, or BP. These results show that the dose of 
urantide used in this study may affect the cellular components and exert effects opposite those of UII on atherosclerotic plaques in rabbits. UII is reportedly involved in the progression of atherosclerosis by activating both its specific and common pathway and then regulating inflammation and cell proliferation [46-48]. Although the dose of urantide used did not significantly change the biological progression mentioned, it affected the plaque composition by inhibiting macrophage-derived foam cell formation.

Endothelial cells play an important role in atherosclerotic plaque initiation [49]. In vitro experiments with UII and urantide in cultured HUVECs were also performed in this study. The upregulation of VCAM-1 and ICAM- 1 by UII was partially reversed by urantide. These results were consistent with a previous report involving human coronary endothelial cells [50]. UII is believed to participate in the atherogenesis process from initiation to progression. Taken together, these results provide direct evidence of the role of macrophage-expressed UII in atherogenesis. Atherogenesis involves not only circulating UII but also local tissue or cell-secreted UII, and blocking UII/UTR by urantide may promote plaque stability by decreasing the number of macrophage-derived foam cells. Atherosclerosis is a disease associated with aging that progresses faster in postmenopausal women than in men. As such, the development of potent and selective drugs based on the urotensinergic system will have high potential clinical value in the treatment of atherosclerosis.

\section{ACKNOWLEDGEMENTS}

This study was supported by grants from the National Natural Science Foundation of China (81370379 and 30900526 to SHZ), the Natural Science Foundation of Shaanxi Province (2017BSHQYXMZZ18 to YFL, 2012KJXX-07, 2014JQ4137 to SHZ and 2014FWPT07 to EQL) and the Fundamental Research Fund for the Central Universities (SHZ). We thank $\mathrm{HZ}$ and $\mathrm{HLC}$ for their technical assistance.

\section{AUTHOR CONTRIBUTIONS}

QQY, DXC, LRX, YL, YFL, HLL, YKL, XYZ, and SHZ performed the experiments and analyzed the data. SHZ, EQL, QQY, and JLF Fan designed this project, analyzed the data, and wrote the paper. LB and RW helped to analyze the data and performed some of the experiments. SHZ, EQL, and JLF supervised the experiments and revised the paper. All of the authors have read and approved the final paper.

\section{ADDITIONAL INFORMATION}

The online version of this article (https://doi.org/10.1038/s41401-019-0315-8) contains supplementary material, which is available to authorized users.

Competing interests: The authors declare no competing interests.

\section{REFERENCES}

1. Mozaffarian D, Benjamin EJ, Go AS, Arnett DK, Blaha MJ, Cushman M, et al. Heart disease and stroke statistics-2015 update: a report from the American Heart Association. Circulation. 2015;131:e29-322.

2. Moran AE, Roth GA, Narula J, Mensah GA. 1990-2010 global cardiovascular disease atlas. Glob Heart. 2014;9:3-16.

3. WHO, World Heart Federation, World Stroke Organization. Global atlas on cardiovascular disease prevention and control, Policies, strategies and interventions. Geneva, Switzerland: The International Organization; 2011. p. 164. https://www. who.int/cardiovascular_diseases/publications/atlas_cvd/en/. Accessed 8 Jul 2019.

4. Watanabe T, Sato K, Itoh F, Noguchi Y, Fujimoto K, Koyama T, et al. Emerging roles for vasoactive peptides in diagnostic and therapeutic strategies against atherosclerotic cardiovascular diseases. Curr Protein Pept Sci. 2013;14:472-80.

5. Weber C, Zernecke A, Libby P. The multifaceted contributions of leukocyte subsets to atherosclerosis: lessons from mouse models. Nat Rev Immunol. 2008;8:802-15.

6. Winkels $H$, Ehinger E, Vassallo M, Buscher K, Dinh HQ, Kobiyama K, et al. Atlas of the immune cell repertoire in mouse atherosclerosis defined by single-cell RNAsequencing and mass cytometry. Circ Res. 2018;122:1675-88.
7. Douglas SA, Ohlstein EH. Human urotensin-II, the most potent mammalian vasoconstrictor identified to date, as a therapeutic target for the management of cardiovascular disease. Trends Cardiovasc Med. 2000;10:229-37.

8. Pearson D, Shively JE, Clark BR. Geschwind, II, Barkley M, Nishioka RS, et al. Urotensin II: a somatostatin-like peptide in the caudal neurosecretory system of fishes. Proc Natl Acad Sci USA. 1980;77:5021-4.

9. Al Kindi H, Hafiane A, You Z, Albanese I, Pilote L, Genest J, et al. Circulating levels of the vasoactive peptide urotensin II in patients with acute coronary syndrome and stable coronary artery disease. Peptides. 2014;55:151-7.

10. Ban $Y$, Watanabe $T$, Suguro $T$, Matsuyama $T A$, Iso $Y$, Sakai $T$, et al. Increased plasma urotensin-II and carotid atherosclerosis are associated with vascular dementia. J Atheroscler Thromb. 2009;16:179-87.

11. Suguro $T$, Watanabe $T$, Ban $Y$, Kodate $S$, Misaki $A$, Hirano $T$, et al. Increased human urotensin II levels are correlated with carotid atherosclerosis in essential hypertension. Am J Hypertens. 2007;20:211-7.

12. Suguro $T$, Watanabe $T$, Kodate $S, X u$ G, Hirano $T$, Adachi $M$, et al. Increased plasma urotensin-II levels are associated with diabetic retinopathy and carotid atherosclerosis in Type 2 diabetes. Clin Sci (Lond). 2008;115:327-34.

13. Heringlake $M$, Kox T, Uzun O, Will B, Bahlmann L, Klaus $S$, et al. The relationship between urotensin II plasma immunoreactivity and left ventricular filling pressures in coronary artery disease. Regul Pept. 2004;121:129-36.

14. Lapp H, Boerrigter G, Costello-Boerrigter LC, Jaekel K, Scheffold T, Krakau I, et al. Elevated plasma human urotensin-II-like immunoreactivity in ischemic cardiomyopathy. Int J Cardiol. 2004;94:93-7.

15. Li Y, Zhao S, Wang Y, Chen Y, Lin Y, Zhu N, et al. Urotensin II promotes atherosclerosis in cholesterol-fed rabbits. PLoS ONE. 2014;9:e95089.

16. Shiraishi $Y$, Watanabe $T$, Suguro $T$, Nagashima M, Kato R, Hongo $S$, et al. Chronic urotensin II infusion enhances macrophage foam cell formation and atherosclerosis in apolipoprotein E-knockout mice. J Hypertens. 2008;26:1955-65.

17. Zhao S, Li Y, Gao S, Wang X, Sun L, Cheng D, et al. Autocrine human urotensin II enhances macrophage-derived foam cell formation in transgenic rabbits. Biomed Res Int. 2015;2015:843959.

18. Lutgens E, van Suylen RJ, Faber BC, Gijbels MJ, Eurlings PM, Bijnens AP, et al. Atherosclerotic plaque rupture: local or systemic process? Arterioscler Thromb Vasc Biol. 2003;23:2123-30.

19. Virmani R, Kolodgie FD, Burke AP, Finn AV, Gold HK, Tulenko TN, et al. Atherosclerotic plaque progression and vulnerability to rupture: angiogenesis as a source of intraplaque hemorrhage. Arterioscler Thromb Vasc Biol. 2005; 25:2054-61.

20. Businaro R, Tagliani A, Buttari B, Profumo E, Ippoliti F, Di Cristofano C, et al. Cellular and molecular players in the atherosclerotic plaque progression. Ann N Y Acad Sci. 2012;1262:134-41.

21. Shah PK. Mechanisms of plaque vulnerability and rupture. J Am Coll Cardiol. 2003;41:15S-22S.

22. Li S, Wang YN, Niimi M, Ning B, Chen Y, Kang D, et al. Angiotensin II destabilizes coronary plaques in Watanabe heritable hyperlipidemic rabbits. Arterioscler Thromb Vasc Biol. 2016;36:810-6.

23. You Z, Genest J Jr, Barrette PO, Hafiane A, Behm DJ, D'Orleans-Juste P, et al. Genetic and pharmacological manipulation of urotensin II ameliorate the metabolic and atherosclerosis sequalae in mice. Arterioscler Thromb Vasc Biol. 2012;32:1809-16.

24. Lu H, Rateri DL, Feldman DL, Charnigo RJ Jr, Fukamizu A, Ishida J, et al. Renin inhibition reduces hypercholesterolemia-induced atherosclerosis in mice. J Clin Invest. 2008;118:984-93.

25. Cinar N, Gurlek A. Association between novel adipocytokines adiponectin, vaspin, visfatin, and thyroid: An experimental and clinical update. Endocr Connect. 2013:2:R30-8.

26. Ni X, Zhang J, Tang C, Qi Y. Intermedin/adrenomedullin 2: an autocrine/ paracrine factor in vascular homeostasis and disease. Sci China Life Sci. 2014;57:781-9.

27. Fan J, Kitajima S, Watanabe T, Xu J, Zhang J, Liu E, et al. Rabbit models for the study of human atherosclerosis: from pathophysiological mechanisms to translational medicine. Pharmacol Ther. 2015;146:104-19.

28. Daugherty A, Tall AR, Daemen M, Falk E, Fisher EA, Garcia-Cardena G, et al. Recommendation on design, execution, and reporting of animal atherosclerosis studies: A scientific statement from the American Heart Association. Circ Res. 2017;121:e53-79.

29. Patacchini R, Santicioli $P$, Giuliani S, Grieco P, Novellino E, Rovero $P$, et al. Urantide: an ultrapotent urotensin II antagonist peptide in the rat aorta. $\mathrm{Br} J$ Pharmacol. 2003;140:1155-8.

30. Waqar AB, Koike T, Yu Y, Inoue T, Aoki T, Liu E, et al. High-fat diet without excess calories induces metabolic disorders and enhances atherosclerosis in rabbits. Atherosclerosis. 2010;213:148-55.

31. Wolf D, Zirlik A, Ley K. Beyond vascular inflammation-recent advances in understanding atherosclerosis. Cell Mol Life Sci. 2015;72:3853-69. 
32. Zhang G, Li C, Zhu N, Chen Y, Yu Q, Liu E, et al. Sex differences in the formation of atherosclerosis lesion in apoE(-/-)mice and the effect of 17 beta-estrodiol on protein S-nitrosylation. Biomed Pharmacother. 2018;99:1014-21.

33. Chiba T, Ikeda M, Umegaki K, Tomita T. Estrogen-dependent activation of neutral cholesterol ester hydrolase underlying gender difference of atherogenesis in apoE-/- mice. Atherosclerosis. 2011;219:545-51.

34. Buko VU, Lukivskaya O, Naruta E, Popov Y, Chirkin A, Chirkina I, et al. Antiatherogenic effects of 17 beta-estradiol and 17 alpha-estradiol and its derivative J811 in cholesterol-fed rabbits with thyroid inhibition. Climacteric. 2001;4:49-57.

35. Bruck B, Brehme U, Gugel N, Hanke S, Finking G, Lutz C, et al. Gender-specific differences in the effects of testosterone and estrogen on the development of atherosclerosis in rabbits. Arterioscler Thromb Vasc Biol. 1997;17:2192-9.

36. Hanash KA, Kottke BA, Greene LF, Titus JL. Effects of conjugated estrogens on spontaneous atherosclerosis in pigeons. Arch Pathol. 1972;93:184-9.

37. Hanke H, Hanke S, Finking G, Muhic-Lohrer A, Muck AO, Schmahl FW, et al Different effects of estrogen and progesterone on experimental atherosclerosis in female versus male rabbits. Quantification of cellular proliferation by bromodeoxyuridine. Circulation. 1996;94:175-81.

38. Hough JL, Zilversmit DB. Effect of 17 beta estradiol on aortic cholesterol content and metabolism in cholesterol-fed rabbits. Arteriosclerosis. 1986;6:57-63.

39. Esper E, Chan EK, Buchwald H. Natural history of atherosclerosis and hyperlipidemia in heterozygous WHHL (WHHL-Hh) rabbits. I. The effects of aging and gender on plasma lipids and lipoproteins. J Lab Clin Med. 1993;121:97-102.

40. Johns DG, Ao Z, Naselsky D, Herold CL, Maniscalco K, Sarov-Blat L, et al. Urotensin-II-mediated cardiomyocyte hypertrophy: effect of receptor antagonism and role of inflammatory mediators. Naunyn Schmiedebergs Arch Pharmacol. 2004;370:238-50.

41. Kiss RS, You Z, Genest J Jr, Behm DJ, Giaid A. Urotensin II differentially regulates macrophage and hepatic cholesterol homeostasis. Peptides. 2011;32:956-63.
42. Watanabe T, Suguro T, Kanome T, Sakamoto $Y$, Kodate $S$, Hagiwara $T$, et al. Human urotensin II accelerates foam cell formation in human monocyte-derived macrophages. Hypertension. 2005;46:738-44.

43. Rodriguez-Moyano M, Diaz I, Dionisio N, Zhang X, Avila-Medina J, CalderonSanchez $E$, et al. Urotensin-II promotes vascular smooth muscle cell proliferation through store-operated calcium entry and EGFR transactivation. Cardiovasc Res. 2013;100:297-306.

44. Bousette N, D'Orleans-Juste P, Kiss RS, You Z, Genest J, Al-Ramli W, et al. Urotensin II receptor knockout mice on an ApoE knockout background fed a high-fat diet exhibit an enhanced hyperlipidemic and atherosclerotic phenotype. Circ Res. 2009;105:686-95.

45. Brancaccio D, Limatola A, Campiglia P, Gomez-Monterrey I, Novellino E, Grieco P, et al. Urantide conformation and interaction with the urotensin-II receptor. Arch Pharm. 2014;347:185-92.

46. Barrette PO, Schwertani AG. A closer look at the role of urotensin II in the metabolic syndrome. Front Endocrinol. 2012;3:165.

47. Chatenet $D$, Nguyen $\Pi$, Letourneau $M$, Fournier A. Update on the urotensinergic system: new trends in receptor localization, activation, and drug design. Front Endocrinol. 2012;3:174.

48. Jarry $M$, Diallo $M$, Lecointre $C$, Desrues $L$, Tokay $T$, Chatenet $D$, et al. The vasoactive peptides urotensin II and urotensin II-related peptide regulate astrocyte activity through common and distinct mechanisms: involvement in cell proliferation. Biochem J. 2010;428:113-24.

49. Jensen HA, Mehta JL. Endothelial cell dysfunction as a novel therapeutic target in atherosclerosis. Expert Rev Cardiovasc Ther. 2016;14:1021-33.

50. Cirillo P, De Rosa S, Pacileo M, Gargiulo A, Angri V, Fiorentino I, et al. Human urotensin II induces tissue factor and cellular adhesion molecules expression in human coronary endothelial cells: an emerging role for urotensin II in cardiovascular disease. J Thromb Haemost. 2008;6:726-36. 